\title{
CLÁUSULAS ABUSIVAS Y SU REGULACIÓN A LA LUZ DE LA LEY 1480 DE 2011: ¿COMPATIBILIDAD O DICOTOMÍA?*
}

\author{
Andrea Carolina Pérez Forero**
}

Fecha de recibido: 10 de agosto de 2013

Fecha de aprobado: 1 de octubre de 2013

Artículo resultado de investigación

Forma de citación: Pérez, A. (2013). Cláusulas abusivas y su regulación a la luz de la Ley 1480 de 2011- Compatibilidad o dicotomía. Revista Prolegómenos. Derechos y Valores, 16, 32, 159-174.

\section{Resumen}

El presente trabajo tiene como objetivo principal evaluar desde un análisis normativo la afinidad o incompatibilidad de los criterios que regulan lo concerniente a las cláusulas abusivas y su inserción en un contrato de adhesión, cuyo origen se tenga en una relación de consumo.

Se trata de una investigación predominantemente teórica, que se propone estudiar, a la par con lo dispuesto en el actual Estatuto del Consumidor, las disposiciones que sobre el tema de cláusulas abusivas se encuentran vigentes y que directa o indirectamente tienen incidencia sobre el régimen de protección establecido por este, al regular las condiciones de consumo para algunos sectores de la economía, puntualmente el sector financiero, el sector de servicios públicos domiciliarios y el sector de las telecomunicaciones; evidenciando así las posibles contradicciones entre estás y lo establecido de manera general en la Ley 1480 de 2011.

\section{Palabras clave}

Cláusulas abusivas, estatuto del consumidor, contrato de adhesión, regímenes especiales, consumidor.

\footnotetext{
* El presente artículo es resultado del proyecto denominado "Protección contractual para el consumidor en Colombia desde la perspectiva de la Ley 1480 de 2011, en materia de cláusulas abusivas" financiado por el fondo de investigaciones de la Vicerrectoría de Investigaciones de la UMNG, perteneciente al Grupo de Derecho Privado del Centro de Investigaciones Jurídicas, Políticas y Sociales de la Facultad de Derecho de la Universidad Militar Nueva Granada. Investigadora principal Dra. Andrea Carolina Pérez Forero.

** Abogada Magna Cum Laude de la Universidad Militar Nueva Granada. Especialista en Derecho Contractual y en Derecho Comercial de la Universidad del Rosario. Diplomada en Docencia Universitaria, en Didáctica Universitaria y en Uso y Apropiación de las TIC. Docente de planta e investigadora de la Facultad de Derecho de la Universidad Militar Nueva Granada. Correo electrónico: andrea.perez@unimilitar.edu.co
} 


\title{
ABUSIVE CLAUSES AND THEIR REGULATION IN THE LIGHT OF LAW 1480 OF 2011: COMPATIBILITY OR DICHOTOMY?
}

\begin{abstract}
The main objective of this work is to assess the incompatibility or affinity, from a normative analysis, of regulating criteria concerning abusive clauses and their insertion in an adhesion contract, whose origin is from a consumer relationship.

It is a predominantly theoretical research that aims to study, together with the current Consumer Statute, the enforced provisions regarding abusive clauses that have an impact on the protection provided by the Statute, directly or indirectly, regulating the consuming conditions for some sectors of the economy, more precisely the financial sector, the public utilities sector and the telecommunications sector, thus showing possible contradictions between these provisions and what was established on Law 1480 of 2011.
\end{abstract}

\section{Keywords}

Abusive Clauses, Consumer Statute, Adhesion Contract, Special Regimes, Consumer.

\section{CLÁUSULAS ABUSIVAS E SUA REGULAMENTAÇÃO NO CONTEXTO DA LEI 1.480 DE 2011: ¿COMPATIBILIDADE OU DICHOTOMY?}

\section{Resumo}

O principal objetivo deste trabalho é avaliar a incompatibilidade ou de afinidade, a partir de uma análise normativa, de regular os critérios relativos às cláusulas abusivas e sua inserção em um contrato de adesão, cuja origem é a partir de uma relação de consumo.

É uma pesquisa predominantemente teórica que tem como objetivo estudar, em conjunto com o Estatuto do Consumidor vigente, as disposições aplicadas em relação a cláusulas abusivas que têm um impacto sobre a proteção fornecida pelo Estatuto, direta ou indiretamente, que regulamenta as condições de consumo para alguns setores da economia, mais precisamente o sector financeiro, o setor de serviços públicos e do setor de telecomunicações, mostrando, assim, possíveis contradições entre essas disposições e que foi estabelecido em Lei 1480 de 2011.

\section{Palavras-Chave}

Cláusulas abusivas, Lei do consumidor, Contrato de adesão, Regimes especiais, Consumidor.

\section{INTRODUCCIÓN}

Las circunstancias que giran en torno a la relación consumidor - productor han generado en el mundo entero la necesidad de crear andamiajes jurídicos lo suficientemente garantistas para proteger a la parte más vulnerable de esta relación contractual, lo cual a todas luces resulta apropiado y sobre todo acorde con los fines que los Estados se han propuesto, diseñados en aras de proteger a sus administrados; fines estos que irradian sus efectos sobre principios tan propios del mundo negocial como lo es el principio de la autonomía de la libertad privada. 
La superación por parte del Estado de esos principios ha permitido llegar a coartar, al menos en cierta medida, la arremetida de los capitalistas quienes, aprovechando su poderío económico, han ido monopolizando paulatinamente industrias completas y sectores económicos, lo que les ha puesto en la condición de ser quienes predisponen las condiciones del "juego" económico ante una sociedad altamente consumista.

Tal intervención estatal ciertamente no ha sido pacífica, los principios y reglas que gobiernan el ciclo normal de las transacciones comerciales bajo las que se comercializan bienes y servicios van en contra de ese tipo de medidas, lo que deviene lógico, ya que la dinámica misma del comercio siempre ha procurado la practicidad y no por alguna formalidad implícita siempre en tal intervención, que hoy se manifiesta con las disposiciones previstas en el actual Estatuto del Consumidor. Y es precisamente respecto de los consumidores que vale la pena entrar a analizar si lo dispuesto hasta el momento, al menos jurídicamente, se consolida como una herramienta efectiva y útil para hacer valer sus derechos, más aun cuando estos representan el extremo "débil" en la relación que deriva de un contrato cuyo contenido se encuentra preestablecido.

Así las cosas, puede decirse que el interrogante sobre el que versa el problema de investigación planteado se remite a cuestionar ¿̇cuál ha sido la protección contractual dada al consumidor en Colombia, a partir de la expedición de la ley 1480 de 2011 y lo establecido en materia de cláusulas abusivas? Para responderlo, se abordará una investigación básica, jurídica y teórica que permitirá analizar el andamiaje normativo que rige actualmente el tema, haciendo énfasis en el estudio de las normas que le protegen contractualmente ante la imposición de una cláusula abusiva, considerando, para ello, no solo lo expuesto en la Ley 1480 de 2011 sino también en regímenes especiales que regulan lo propio sobre esta materia y que, por disposición del mismo Estatuto, tienen aplicación preferente; lo que servirá para determinar si, al menos normativamente, existen deficiencias o contradicciones que impiden la efectiva protección de los derechos del consumidor debido a la dicotomía entre régimen especial y Estatuto general del consumidor.

El método empleado es el teórico de tipo analítico, que nos permitirá ir estudiando paso a paso los alcances de la norma propuesta para la investigación, y la suficiencia respecto de su aplicación. De igual forma, se considerará inicialmente un método histórico, para la determinación crítica de los antecedentes de la regulación vigente.

Con el objetivo de abordar de una manera más sencilla el tema de la protección contractual al consumidor, específicamente en lo que concierne al establecimiento de cláusulas abusivas, se hará inicialmente un acercamiento general al derecho del consumo para, posteriormente, ahondar en el estudio del Estatuto del consumidor y así evaluar lo propio sobre las cláusulas abusivas examinando conjuntamente lo dispuesto en tres regímenes especiales: financiero, de comunicaciones y de servicios públicos domiciliarios, finalizando con el análisis respecto de la dicotomía o complementariedad que pudiera generarse entre las disposiciones del Estatuto y las de los regímenes especiales.

\section{DERECHO DEL CONSUMO}

Resulta necesario realizar un ejercicio reflexivo sobre la aparición del derecho del consumo. El nacimiento de este no se dio de forma fortuita, necesitó de varias décadas y esfuerzos para tener la importancia que hoy en día goza en el concierto internacional y, poco a poco, en Colombia. La necesidad de proteger a los consumidores nace evidentemente cuando las relaciones contractuales se convierten en un juego económico desequilibrado y altamente abusivo frente al consumidor.

Examinar la historia del derecho al consumo excede los intereses de este trabajo, pero se 
hará una breve referencia siguiendo a Villalba (2009, pp. 78-82). Señala el autor que la imperiosidad por regular la situación de los consumidores por medio del ordenamiento jurídico es consecuencia del desarrollo de los países capitalistas de occidente. El hombre paso de ser una medida, una estadística económica, para convertirse en sujeto con derechos, derechos que debían ser protegidos; fue entonces, en Estados Unidos, que iniciaron las organizaciones en pro de los derechos de los consumidores, las autoridades políticas y ejecutivas decidieron también apoyar la causa (2009, p. 79).

Una de las sociedades más consumista de la historia se vio empujada a regular y proteger los derechos e intereses de los consumidores, pues temas como la seguridad o la información se vieron relegados frente a asuntos supremamente superficiales, tales como el diseño de los carros (Villalba, 2009, p. 80). Esta tendencia de normativizar lo relacionado con el consumidor llegó a Europa. Un hecho que resulta para nosotros de mayúscula importancia es lo mencionado en la reunión de jefes de Estado que tuvo lugar en París en el año 1972:

(...) se determinó que la Comunidad debería buscar ir más allá de la expansión económica y propender por mejorar las condiciones de vida y de trabajo de sus ciudadanos, para lo cual deberían adoptarse nuevas políticas en materia de mejoramiento de las medidas adoptadas para proteger a los consumidores (Villalba, 2009, p. 80).

El trasfondo de esa posición se genera al elegir entre las condiciones de vida y la expansión económica porque, en realidad, la tensión que subyace del tema en cuestión es el hombre, en este caso el consumidor, versus el ánimo capitalista y, por supuesto, el ánimo de dominar todo un sector económico y financiero.

En Colombia, las leyes en pro de los consumidores llegarían por medio del Decreto 3466 de 1982, "Por el cual se dictan normas relativas a la idoneidad, la calidad, las garantías, las marcas, las leyendas, las propagandas y la fijación pública de precios de bienes y servicios, la responsabilidad de sus productores, expendedores y proveedores, y se dictan otras disposiciones", expedido por el Presidente en virtud de la Ley 73 de 1981 que le otorgó la facultad para regular el tema. Pero antes de pasar a estudiar los diferentes contenidos legales, es preciso definir que debe entenderse por Derecho del consumo.

El derecho del consumo es el conjunto de normas que tiene como primer objetivo la protección de los intereses y los derechos de los consumidores. De esta manera, se restringe, por decirlo de alguna manera, el ámbito de aplicación del derecho del consumo, ya que es imperativo que una de las partes del acto jurídico sea un consumidor (Villalba, 2009, p. 82). Nos adherimos a Villalba cuando menciona que el derecho al consumo surge para tratar de equilibrar la relación de consumo (p. 83), pues es evidente que existe una disparidad en el acceso al conocimiento sobre algunos temas, que resultan a todas luces complicados para el hombre baremo.

Seguidamente, es preciso señalar que el derecho de consumo se encuentra consagrado en la Carta Política, disposición 78:

La ley regulará el control de calidad de bienes y servicios ofrecidos y prestados a la comunidad, así como la información que debe suministrarse al público en su comercialización.

Serán responsables, de acuerdo con la ley, quienes en la producción y en la comercialización de bienes y servicios, atenten contra la salud, la seguridad y el adecuado aprovisionamiento a consumidores y usuarios.

El Estado garantizará la participación de las organizaciones de consumidores y usuarios 
en el estudio de las disposiciones que les conciernen. Para gozar de este derecho las organizaciones deben ser representativas y observar procedimientos democráticos internos.

De la regulación de rango constitucional se pueden vislumbrar varios aspectos importantes. Aparece en la Norma de normas, el deber de informar que recae sobre los productores; amplía esta definición Villalba cuando sentencia que este deber está dirigido a generar en los consumidores un conocimiento "veraz suficiente y claro" sobre las "características, utilidad, forma de utilización, contraindicaciones", es decir, generalidades y especificidades del bien o servicio que lleven al consumidor a decidir libre y conscientemente sobre el producto y así evitar un daño al consumidor (p. 90).

Otro de los elementos que llega a desempeñar un papel importante es el deber de seguridad que recae sobre los productores. La seguridad, en este caso, se refiere puntualmente a la salud de los consumidores, de lo contrario, si se llegase a materializar un daño en su vida o en su integridad por el bien o servicio tendrá el productor que indemnizarlo. De la misma forma, como los productores tienen deberes, los consumidores tienen derechos, como ser informado, a la seguridad, a asociarse, ser escuchado individual o colectivamente, reparación por daños y perjuicios, medio ambiente sano, retracto, igualdad de trato y libre elección de bienes y servicios (p. 91).

Vale la pena mencionar que el derecho de consumo está compuesto por normas de orden público, esto quiere decir que limitan la voluntad de las personas, el andamiaje jurídico que lo compone, coarta el autogobierno de la gente para imponer sus condiciones del contrato.

Es menester continuar con una pequeña introducción al Estatuto del Consumidor, Ley 1480 de 2011, para continuar así con el desarrollo de las cláusulas abusivas.

\section{ESTATUTO DEL CONSUMIDOR}

Como ya se señaló, la ley que rige actualmente en materia de consumo es la 1480 de 2011 que reformó lo dispuesto en el Decreto 3466 de 1982, al cual también ya se hizo referencia. Resulta pertinente ahora conocer sobre quien recae su aplicación, en otras palabras, quién es el consumidor. Esta duda es resuelta por la misma ley en su artículo 5, numeral 3:

(...) Consumidor o usuario. Toda persona natural o jurídica que, como destinatario final, adquiera, disfrute o utilice un determinado producto, cualquiera que sea su naturaleza para la satisfacción de una necesidad propia, privada, familiar o doméstica y empresarial cuando no esté ligada intrínsecamente a su actividad económica. Se entenderá incluido en el concepto de consumidor el de usuario.

Sobre esta definición hay que mencionar que toca no solo al usuario sino también a la persona que se beneficie con el bien o servicio. Existe la limitante de emplear el bien o servicio para su actividad económica, si ello sucediere no podría entendérsele como consumidor (Cámara de Comercio Medellín, Foro del Jurista, 2012, p. 12). El Estatuto tenía y tiene, evidentemente, como objetivo cumplir con equilibrar las relaciones de consumo. Otorgar a los consumidores, parte más vulnerable, suficientes garantías que protejan sus derechos e intereses.

El reciente Estatuto del Consumidor trae consigo importantes premisas, principios y normas rectoras que es necesario tener en cuenta, por eso vale la pena hacer un breve repaso de lo establecido en la regulación sobre el tema en cuestión.

En lo relativo a los principios generales que persigue el Estatuto, se consideran en el artículo $1 .{ }^{\circ}$ : la protección, promoción y garantía de ejercicio de los derechos de los consumidores. Todo ello se ve permeado por la dignidad, que 
por medio de la Constitución Política hace parte de ese núcleo de principios, valores y derechos fundantes del Estado colombiano. A paso se seguido se hace referencia a los derechos que van a ser garantizados, esto es, la protección frente a eventuales riesgos para la salud, vida o integridad de las personas así como de su seguridad; la información y el acceso a ella por parte de los consumidores, también hace su arribo, con el objetivo, mencionado con anterioridad, de permitir escoger libre y conscientemente al consumidor sobre el producto o bien que va a adquirir; la educación del consumidor, tendiente esta a facilitar el entendimiento de los derechos que tiene, para así poder hacerlos efectivos; la prerrogativa para asociarse y fundar organizaciones para la protección de los derechos de los consumidores, garantizando, así, otro principio constitucional como es la participación de la comunidad en las decisiones que resultan ser altamente incisivas en su diario vivir $y$, finalmente, el régimen especial de protección a niños y adolescentes, elongación del ánimo constitucional.

En el artículo $3^{\circ}$, se vislumbra un amplio catálogo de derechos y deberes a favor de los consumidores y usuarios, dentro de los que se resaltan: la calidad en el bien o servicios, la información, la seguridad, el derecho a ser reparados, a reclamar y la aludida protección contractual, sobre la que se señala: Ser protegido de las cláusulas abusivas en los contratos de adhesión, en los términos de la presente ley. A ello pasaremos más adelante. Sin embargo, vale la pena mencionar que los títulos que suceden a lo recién mencionado versan sobre temas de garantías, los procedimientos, entre otros temas de vital importancia pero que exceden los propósitos de este trabajo, por lo que a ello no se hará mención.

La protección contractual es desarrollada en el Título VII. Como primera medida, se señala que las condiciones y cláusulas que generen dudas serán interpretadas a favor del consumidor (artículo 34); también se hace referencia a los productos no requeridos, estos no pueden bajo ninguna circunstancia significar un costo para el consumidor ni una carga de conservación o gasto alguno a menos que haya sido aceptado por parte de él luego de un ofrecimiento (artículo 35). Otra de las prohibiciones se encuentra en la disposición 36 que impide las ventas atadas, es decir, por medio de una artimaña pretender que el consumidor adquiera un producto solo si adquiere otro; el condicionar incentivos y premios también se encuentra prohibido.

En el capítulo II del mismo Título se hace referencia a las Condiciones negociales generales y de los contratos de adhesión. El artículo 37 determina unos mínimos no negociables dentro de los contratos de adhesión, entre ellos encontramos: el informar con anterioridad, y cumpliendo con el deber de suficiencia de la información, al adherente todo lo tocante a efectos y alcance de las condiciones generales. Estas últimas deberán ser no solo concretas sino también completamente claras. Está prohibido por la ley la inclusión de cláusulas que permitan al productor o proveedor, de forma unilateral, modificar el contrato o dejar de cumplir con ciertas obligaciones.

Se hace referencia, de igual forma, a la necesidad de que conste por escrito la aceptación por parte del consumidor de las condiciones generales que haya proveído el productor respecto de los contratos de adhesión (artículo 39). Lo relativo a las cláusulas de permanencia mínima fue regulado en la disposición 41. Resulta imperativo que para la existencia de la cláusula de permanencia se dé la aceptación expresa por parte del consumidor, es necesario también, que se otorgue un beneficio sustancial para aquellos consumidores que se adhieran a las cláusulas. La permanencia no podrá superar el año, por regla general, de la misma forma, esta debe ser ofrecida con otra alternativa o modalidad contractual que no implique la permanencia, permitiendo así al consumidor escoger la que considere más adecuada para la satisfacción de sus necesidades. Después de satisfecho el período de permanencia mínima el consumidor podrá terminar el contrato. 
En este punto del desarrollo consideramos necesario hacer una revisión de lo que debe ser entendido como contrato de adhesión para pasar propiamente a examinar las cláusulas abusivas que, precisamente, están prohibidas de ese tipo de contratos.

El contrato de adhesión se ha convertido en un verdadero modelo contractual para la relación de consumo. Pero ¿qué es un contrato de adhesión? Para responder a esta pregunta acudimos a Ossorio,

Constituye una típica y cada vez más frecuente modalidad de la contratación, que se caracteriza por el hecho de que es una de las partes la que fija las cláusulas o condiciones, iguales para todos, del contrato, cuya celebración se propone, sin que quienes quieran participar en él tengan otra alternativa que aceptarlo o rechazarlo en su totalidad; es decir, adherirse o no a los términos del contrato preestablecido, sin la posibilidad de discutir su contenido (1981, p. 168).

En este tipo de contrato, la libre discusión de las cláusulas no tiene lugar. Una de las partes impone las condiciones del contrato, la parte más fuerte decide qué cláusulas harán parte del contrato, sin consultar ni tener en cuenta al consumidor, que tendrá la posibilidad de aceptar o no, en todas sus partes, el contrato. Los contratos de libre discusión, sin duda, representan un mayor sacrificio de tiempo para su elaboración; es claro que para las relaciones flexibles y agiles que requiere el comercio y las relaciones de consumo actuales, acudir a un contrato de libre discusión sería altamente engorroso. Villalba considera que el uso de este tipo de contratos es el resultado de una mutación en todos los sectores del grupo humano, no solo lo social sino también lo económico y lo político que se ha materializado en una sociedad de consumo $y$, por ende, en venta de bienes y servicios en masa (2011, p. 179).

En el artículo $5^{\circ}$ de la ley 1480, Estatuto del Consumidor, numeral $4^{\circ}$, se define también de forma clara y concisa qué representa un contrato de este tipo. Determina la norma que la característica del contrato de adhesión consiste en que el productor o proveedor dispone de las cláusulas y el consumidor, sin posibilidad alguna de cambiarlas, tiene como prerrogativa aceptar o rechazar las condiciones predispuestas.

Los contratos de adhesión en materia de contratos de consumo se vislumbran, como lo menciona Villalba, en dos formas básicamente: ante la entrega por parte del productor de un formato de contrato previamente redactado, verbigracia, la adquisición de algún servicio por ejemplo una línea de celular o cuando se acude a un establecimiento de venta de bienes y servicios masivos, en este caso, un ejemplo evidente sería Carrefour (p. 181).

Ante la realidad que sobresale, es decir, el desequilibrio contractual entre las partes que componen un contrato de adhesión, es importante señalar que los ordenamientos jurídicos, los Estados y la comunidad internacional han obedecido al llamado de protección de los consumidores, regulando, por medio de regímenes especiales los contratos de adhesión propios de las relaciones de consumo. Como se pudo observar, el Estatuto del Consumidor considera y define lo que debe ser entendido por contrato de adhesión y además impone ciertas normas mínimas de legibilidad, idioma, prohibición de espacios blancos, entre otros, para proteger al consumidor de medidas unilaterales por parte del productor (p. 182).

Resulta pertinente ahora entrar a estudiar las cláusulas abusivas para luego analizar lo que corresponde sobre estas en los regímenes especiales. Como ya se resaltó, en los contratos de adhesión, la participación del consumidor, quien se identifica como la parte débil, se circunscribe única y exclusivamente a la aceptación o no del formato del contrato que ya ha sido preestablecido por la parte dominante; esto en la práctica acarreó un sin número de inconvenientes, pues se evidenció como quien predisponía el contenido del contrato tendía a 
favorecer sus intereses a través de lo dispuesto. Ante tal desigualdad, surgió la necesidad de regular jurídicamente lo relativo a la contratación por adhesión, instituyendo para ello, normas de orden público limitantes de la autonomía contractual. La tendencia al abuso llevó al Estado por medio del derecho a tomar las respectivas medidas para proteger a la parte más vulnerable, para el caso, al consumidor (Echeverri, 2011, p. 127).

Puede entonces considerarse la cláusula abusiva como una sanción, al momento de configurarse una reprobación por parte del ordenamiento frente a una actuación abusiva de quién se encuentre en posición dominante (Suescún de Roa, 2009, p. 8). Sobre el tema, también se ha pronunciado la Corte Suprema de Justicia, sentenciando que la cláusula abusiva opera cuando "se emplea con exceso o anormalidad el poder de negociación para introducir en el contrato estipulaciones que generen un desequilibrio económico injusto o carente de razonabilidad" (Corte Suprema de Justicia, Expediente núm. 3972).

Por primera vez, el ordenamiento jurídico colombiano consagra una regulación sobre las cláusulas abusivas, tema que ya ha sido debatido en instancias internacionales, y sobre el que se han tomado las medidas necesarias para salvaguardar a las partes débiles de las relaciones contractuales. El mejor ejemplo de ello es la Directiva 93/13 promulgada por la Comunidad Económica Europea. El objetivo de esta es evitar que en medio de los contratos celebrados con consumidores se materialice una diferencia considerable por el conducto de una cláusula abusiva en todos los Estados miembros. Para la Directiva, la definición se circunscribe a,

1. Las cláusulas contractuales que no se hayan negociado individualmente se considerarán abusivas si, pese a las exigencias de la buena fe, causan en detrimento del consumidor un desequilibrio importante entre los derechos y obligaciones de las partes que se derivan del contrato.
2. Se considerará que una cláusula no se ha negociado individualmente cuando haya sido redactada previamente y el consumidor no haya podido influir sobre su contenido, en particular en el caso de los contratos de adhesión (artículo 3).

Vemos como la regulación acerca de las cláusulas abusivas tiene el ánimo de generar en alguna medida un equilibrio del consumidor, respecto del productor. Colombia, con su Estatuto del Consumidor, no fue ajena a la problemática y afectación de derechos que provocaba la falta de normatividad sobre el tema de frente a los consumidores. En el artículo 42 de la Ley 1480 de 2011 se consagra el concepto de cláusula abusiva, reafirmando lo que se ha venido mencionando, esto es, una cláusula que provoca un desequilibrio que afecta sin justificación al consumidor; señala la norma que el tamaño del desequilibrio dependerá y se evaluará concretamente. Al referirse a la inclusión por parte de los productores y proveedores de cláusulas abusivas en los contratos, estas serán ineficaces de pleno derecho (sin necesidad de demostrarlo con acervo probatorio).

La forma de sancionar este tipo de cláusulas puede por medio de lista, es decir, enlistar un conjunto de cláusulas que serán tenidos como abusivos sin más. De estas hay tres tipos: la lista negra, son cláusulas abusivas y no se admite prueba en contrario (presunción de derecho); la segunda, las listas grises, se tienen en primera instancia como abusivas pero eventualmente podría probarse lo contrario $y$, finalmente, las listas blancas, que no tienen ninguna clase de presunción (Gual, cit., en Villalba, 2011, p.187).

El Estatuto acude a la especie de lista negra. En el artículo 43 se señalan que las cláusulas serán ineficaces de pleno derecho cuando,

1. Limiten la responsabilidad del productor o proveedor de las obligaciones que por ley les corresponden;

2. Impliquen renuncia de los derechos del consumidor que por ley les corresponden; 
3. Inviertan la carga de la prueba en perjuicio del consumidor;

4. Trasladen al consumidor o un tercero que no sea parte del contrato la responsabilidad del productor o proveedor;

5. Establezcan que el productor o proveedor no reintegre lo pagado si no se ejecuta en todo o en parte el objeto contratado;

6. Vinculen al consumidor al contrato, aun cuando el productor o proveedor no cumpla sus obligaciones;

7. Concedan al productor o proveedor la facultad de determinar unilateralmente si el objeto y la ejecución del contrato se ajusta a lo estipulado en el mismo;

8. Impidan al consumidor resolver el contrato en caso que resulte procedente excepcionar el incumplimiento del productor o proveedor, salvo en el caso del arrendamiento financiero;

9. Presuman cualquier manifestación de voluntad del consumidor, cuando de esta se deriven erogaciones $\mathrm{u}$ obligaciones a su cargo;

10. Incluyan el pago de intereses no autorizados legalmente, sin perjuicio de la eventual responsabilidad penal.

11. Para la terminación del contrato impongan al consumidor mayores requisitos a los solicitados al momento de la celebración del mismo, o que impongan mayores cargas a las legalmente establecidas cuando estas existan;

12. Restrinjan o eliminen la facultad del usuario del bien para hacer efectivas directamente ante el productor $\mathrm{y} / \mathrm{o}$ proveedor las garantías a que hace referencia la presente ley, en los contratos de arrendamiento financiero $y$ arrendamiento de bienes muebles.

13. Cláusulas de renovación automática que impidan al consumidor dar por terminado el contrato en cualquier momento o que imponga sanciones por la terminación anticipada, a excepción de lo contemplado en el artículo 41 de la presente ley.
Cuando una cláusula resulte abusiva, y por ende nula o ineficaz, esta afectará únicamente la cláusula viciada y no la totalidad del contrato, siempre y cuando el negocio jurídico pueda subsistir sin la cláusula. El juez, en caso de subsistir el contrato, definirá los derechos y obligaciones que emerjan del contrato subsistente (Ley 1480 de 2011, artículo 44), esto último en pro del principio de preservación del contrato (Rengifo cit., en: Echeverri, 2011, p.138).

Dentro de los controles de las cláusulas abusivas, se encuentra evidentemente el que realiza el Estado que ejerce una función de control ya que, como hemos tenido oportunidad de examinar, los contratos de consumo se caracterizan por el uso de los contratos de adhesión, lo que impide que inter partes puedan solucionar o dirimir el inconveniente respecto de la cláusula que afecta sus derechos. Este último puede realizarse desde tres focos: administrativo, legislativo o judicial. La articulación de estos controles puede darse a priori, así lo señala la autora cuando menciona dentro de este tipo a las autoridades que vigilan actividades bancarias o bursátiles o incluso los servicios públicos domiciliarios, ante estos eventos el control radica en conocer de antemano los contratos que serán puestos a disposición de los consumidores, para así ser aceptados. El control administrativo posterior recae en los organismos estatales que sancionan aquellos contratantes que incluyan cláusulas abusivas en los contratos predeterminados, un ejemplo de ello sería la Superintendencia de Industria y Comercio (Echeverri, 2011, p. 137). El control legislativo es previo por medio de listados de cláusulas negras y las cláusulas grises, tema al que se hizo mención con anterioridad para mostrar las consagradas en el artículo 43 del Estatuto del Consumidor.

El control judicial es ejercido por el juez y se da cuando se está frente a una cláusula abierta, es decir, el juez es quien decide, según los supuestos de hecho del caso en concreto, si efectivamente procede la calificación de una cláusula como abusiva o no. (Echeverri, 2011, p. 138). 
Después de esta exposición sumaria, es necesario hacer una salvedad. Lo recién expuesto hace parte del Estatuto del Consumidor en lo referente a cláusulas abusivas; sin embargo, y por mandato del mismo instrumento legal, en su artículo $2 .^{\circ}$ inciso tercero, se ha determinado que la aplicación de las disposiciones del Estatuto se desplegaran sobre "todos los sectores de la economía respecto de los cuales no exista regulación especial, evento en el cual aplicará la regulación especial y suplementariamente las normas establecidas en esta Ley".

Por ello es menester pasar a estudiar los regímenes especiales escogidos: bancario, de servicios públicos domiciliarios y de telecomunicaciones.

\section{REGÍMENES ESPECIALES}

\subsection{Régimen Financiero}

En materia del régimen financiero, hay que mencionar que la ley que integra los postulados del mismo es la 1328 de 2009, "Por la cual se dictan normas de materia financiera, de seguros, del mercado de valores y otras disposiciones", completando el marco jurídico que regula lo concerniente al consumidor financiero encontramos las Circulares externas 038 y 039 de 2011.

En lo relativo con las cláusulas abusivas, el artículo $7^{\circ}$ literal e) se realiza una elongación del Estatuto del Consumidor, la disposición versa sobre la abstención o prohibición para las entidades vigiladas, de carácter financiero, a la hora de incluir condiciones que deriven en abusos contractuales, cláusulas que afecten el equilibrio contractual $y$, finalmente, un abuso de la posición dominante en la que objetivamente se encuentran.

Las cláusulas abusivas fueron desarrolladas en artículo 11 de la Ley 1328, prohibiendo el uso, en los contratos de adhesión, de estipulaciones que signifiquen: limitaciones o renuncia a los de- rechos de los consumidores financieros; que se invierta la carga de la prueba en detrimento del consumidor; los espacios en blanco, no detallados en carta de instrucciones; aquellas regulaciones que pretendan limitar derechos de consumidores, deberes propios de las entidades vigiladas o incluso cláusulas que exoneren a éstas últimas de responsabilidad y que deriven en un perjuicio para el consumidor financiero; $y$ la última señala "las demás que establezca de manera previa y general la Superintendencia Financiera de Colombia”. En el parágrafo del artículo 11 se señala que las condiciones o cláusulas abusivas incluidas en los contratos se entenderán como no escritas o sin efectos para el consumidor.

Sobre esta regulación, varios han sido los pronunciamientos de la Corte Constitucional señalando que el artículo en mención, es decir, la disposición 11 prohíbe de forma expresa la incorporación de cláusulas abusivas a los contratos de adhesión (MP. Jorge Iván Palacio Palacio. Sentencia T-136 de 2013). Ha dicho el Tribunal Constitucional que "la protección constitucional al consumidor se inspira en el deber de fortalecer sus derechos frente a los productores y distribuidores, dada la desigualdad y la asimetría en que se desenvuelve la persona que acude al mercado, de cualquier bien o servicio, para satisfacer sus necesidades" (M.P Nilson Pinilla Pinilla. Sentencia C-909 de 2012), argumento que soporta finalmente la existencia del derecho al consumo y la necesidad de que el Estado actúe en pro de los más vulnerables en las relaciones contractuales que tienen por objetivo satisfacer los requerimientos de la población.

La intervención directa de la Superintendencia Financiera en la denominación de cláusulas abusivas no ha sido de pacífico recibo. Ante estas inconformidades, la Corte Constitucional ha mencionado que la Superintendencia Financiera es un organismo público técnico por medio del cual el Presidente de la República "ejerce en este ámbito las funciones específicas de policía administrativa (Constitución Política, art. 209)"; de la misma manera, se alude en la 
providencia que la denominación, por parte de la Superintendencia, de una cláusula abusiva depende de un "proceder desleal de la entidad vigilada frente al conjunto de expectativas razonables del consumidor financiero", y que genere en la relación un elemento de desequilibrio.

Igualmente, el Tribunal Constitucional protege la facultad de la Superintendencia para disponer de cuáles cláusulas resultarían abusivas, sentenciando que la misma es efectivamente abierta pero no por ello indeterminable, ya que han de ser establecidas con anticipación y de forma general para así generar el impacto deseado en los contratos de adhesión. Finalmente, señala la Corte que el marco en el que se desarrolla la facultad para definir las cláusulas responde a principios tales como "la buena $\mathrm{fe}$, la confianza legítima, el interés público, las posibilidades de negociación, la atención de la asimetría y la superación de las desigualdades en la relación de consumo" (MP. Nilson Pinilla Pinilla. Sentencia C-909 de 2012).

En uso de esa potestad, la Superintendencia Financiera expidió la Circular Externa 039 de 2011, con el objetivo de garantizar la protección de los consumidores, señalando en ella ejemplos de cláusulas abusivas, verbigracia: la limitación al ejercicio del derecho de defensa ante la posibilidad que tenga el consumidor para controvertir las pruebas que haya allegado la entidad vigilada; cláusulas que permitan la modificación unilateral del contrato en aquellos temas que deban ser debatidos por las partes $y$ tener el consentimiento del consumidor serán abusivas; la imposición de un notario para determinados servicios es una cláusula abusiva (Circular Externa 039 de 2011, numeral 10). Para la Superintendencia, la evaluación de si aplica o no una cláusula abusiva respecto del consentimiento expreso del consumidor financiero deberá hacerse en cada caso concreto, verificando el sustrato legal (Superintendencia Financiera, Concepto 95561 de 2012).

Vemos como el papel de la Superintendencia Financiera requiere de una posición proactiva frente a la protección de los consumidores financieros, pues sobre ella recae la facultad de formular previa y claramente las cláusulas que considere, según los principios y fines de las normas, abusivas. La Corte Suprema de Justicia, también, ha tomado las banderas de la defensa de los derechos de los consumidores, $y$ en esa tarea ha mencionado que las "condiciones generales en el contrato por adhesión deben interpretarse a favor del adherente y en el sentido más favorable"; en su momento se refirió a ello sin estar en vigencia el Estatuto del Consumidor, razón por la cual el fundamento jurídico obedecía a la equidad. Sin embargo, hizo la salvedad de que con el nuevo Estatuto y de acuerdo a su artículo 34 las cláusulas debían ser interpretadas a favor del adherente y ante duda prevalece la cláusula más favorable para el mismo. En la misma sentencia, se señaló que la actividad financiera tiene en sí una función social de la cual se derivan responsabilidades y pertenecen al interés público, por ello el Estado interviene en ella; lo anterior, en concordancia con los artículos 334 y 335 de la Carta Política (MP. Arrubla Paucar, 2011, Sentencia de diciembre 14 de 2011).

\subsection{Régimen de telecomunicaciones}

La primera gran regulación para comunicaciones que encontramos es la Ley 1341 de 2009 "Por la cual se definen principios y conceptos sobre la sociedad de la información y la organización de las Tecnologías de la Información y las Comunicaciones (TIC), se crea la Agencia Nacional de espectro y se dictan otras disposiciones". Dentro del desarrollo de los principios orientadores dispuesto en el artículo 2. ${ }^{\circ}$, se hace referencia en el inciso 4 de la protección de los derechos de los usuarios. Bajo este principio, se señala que el Estado tiene el deber de resguardar y proteger los derechos de los usuarios de las tecnologías de la información y de las comunicaciones. De la misma manera, en la disposición 4. ${ }^{a}$ se legítima la intervención estatal en el sector de las tecnologías de la información y de las comunicaciones; una de las razones es, básicamente, proteger los derechos 
de los consumidores, de los usuarios, monitoreando la calidad, eficiencia y la adecuada prestación de los servicios.

Dentro del Título VI, artículo 53, la Ley 1341 reza que el Régimen de Protección al Usuario estará sujeto a lo que expida la Comisión de Comunicaciones y la norma supletoria será evidentemente el régimen general de la protección al consumidor.

En concordancia con lo recién mencionado, la Comisión de Regulación de Comunicaciones expidió la Resolución 3066 del 18 de mayo de 2011, "por la cual se establece el Régimen Integral de Protección de los Derechos de los Usuarios de los Servicios de Comunicaciones". Dentro del articulado, más exactamente en la disposición 14 que regula lo relativo a las cláusulas prohibidas, se reafirma que en los contratos de prestación de servicios en el sector de las comunicaciones no puede contener cláusulas que versen sobre: exclusión y limitación de responsabilidad de los encargados de proveer el servicio; las ventas atadas también se encuentran vetadas, en este caso, obligando al consumidor a adquirir un bien o servicio que carece de relación directa con el objeto contratado, coartando así sin dudas la libertad de elección que tiene el usuario.

La terminación unilateral del contrato por situaciones no contempladas en la ley, deviene también en una cláusula abusiva; la renuncia a los derechos concedidos al consumidor, por medio de alguna cláusula también cataloga a la estipulación como abusiva; las estipulaciones que concedan plazos extralegales para el cumplimiento de las obligaciones en cabeza del proveedor son abusivas, pues abusa de su posición para desequilibrar la relación contractual.

La Superintendencia de Industria y Comercio ha hecho uso de la última herramienta jurídica mencionada, esto es, la Resolución CRC 3066 de 2011, y ha declarado abusivas cláusulas que cercenan no solo las prohibiciones para las cláusulas abusivas sino también los derechos que han sido endilgados a los consumidores o usuarios por medio de esa Resolución, siendo esta una elongación del Estatuto del Consumidor (Superintendencia de Industria y Comercio, Resolución 31471, 2012).

En el artículo 14 de la Resolución 3066 de 2011, en la que regulan las cláusulas abusivas, se determina que "si alguna de estas cláusulas se prevé en el contrato o cualquier otro documento que deba suscribir el usuario, no surtirán efectos jurídicos y se tendrán por no escritas"; vemos como, finalmente, la inaplicación de la cláusula, el tenerse por no escrita, se trasmuta a una ineficacia de pleno derecho. Frente a esta disputa, Villalba ha señalado que termina siendo la ineficacia de pleno derecho la sanción, tanto en materia financiera como en materia de comunicaciones, es decir, una misma sanción, y ante cualquier suspicacia, argumenta que el Estatuto del Consumidor sanciona las cláusulas abusivas con ineficacia de pleno derecho, entonces, ante cualquier fricción jurídica entre los regímenes especiales se acudiría a la norma general (2011, p. 188).

\subsection{Régimen de los servicios públicos domiciliarios}

Por último, la reglamentación sobre servicios públicos domiciliarios se circunscribe a la Ley 142 de 1994, siendo esta la primera en Colombia que tocó el tema de cláusulas abusivas (Cámara de Comercio Medellín, Foro del Jurista, 2012, p. 138). Los servicios públicos a los que es dirigida la ley son: acueducto, alcantarillado, aseo, energía eléctrica, distribución de gas combustible, telefonía fija pública, entre otros (Ley 142 de 1994, artículo 1).

Vestigios de la regulación del Estatuto actual podían ser divisados en ese momento, hablamos por ejemplo de la disposición 11.1 que explícitamente ordena a las entidades prestadoras del servicio público asegurarse de la óptima, continua y eficiente prestación del servicio de que se trate, además, prohíbe el abuso de la posición dominante frente a sus usuarios. 
En la Ley 142 se dedicó el artículo 133 para fijar una lista de las posibles cláusulas que se presumen abusivas. En caso de no serlo solo podrían ser desvirtuadas de dos formas: primero, que "si al revisarse el contrato en su conjunto se encuentran equilibradas las disposiciones consideradas abusivas con las obligaciones especiales que asume la empresa, y (ii) si la comisión respectiva de la Superintendencia autorizó su inclusión" (Cámara de Comercio Medellín, Foro del Jurista, 2012, p. 140).

Valga la pena mencionar que las cláusulas abusivas vienen presentadas bajo la figura de abuso de la posición dominante; sin embargo, encontramos cláusulas que han sido refrendadas por el Estatuto General y los Especiales. Estipulaciones tales como: la exclusión y limitación de la responsabilidad de la empresa prestadora del servicio o el traslado de la carga probatoria de la empresa al usuario; la disolución del contrato o cambio de condiciones por razones no amparadas en la ley, también deviene en una cláusula abusiva; las que condicionen el consentimiento, evitando así la libre decisión del consumidor o usuario.

La renuncia por medio de estipulaciones o cláusulas de derechos en cabeza del usuario es tenida como abusiva; las cláusulas que otorgan a la empresa prestadora de servicios un plazo más prolongado para el cumplimiento de sus obligaciones son también abusivas, pues una vez más demuestra con esas condiciones una actuación abusiva de su posición. La sanción frente a una cláusula abusiva es la anulación de la viciada, ya que el resto de estipulaciones mantendrán su validez, todo ello de acuerdo con el artículo en discusión.

Sobre este régimen especial, ha mencionado la Superintendencia de Servicios Públicos Domiciliarios que los análisis han de realizarse conforme a la Ley 142 ya que el Estatuto del Consumidor no trastocó ninguna de las regulaciones que en él se desarrollan (Superintendencia de Servicios Públicos Domiciliarios Concepto 674 de 2011).

\section{CONCLUSIONES}

El Estatuto del Consumidor, reglamentación materializada del Derecho al Consumo, ha otorgado, sin lugar a dudas, un nuevo estadio a la relación consumidor-usuario / productor-proveedor. Al examinar la historia del nacimiento del derecho al consumo, es posible entender que su surgimiento se debió a una verdadera necesidad que residía en la obligación estatal de interceder por las personas que terminaban siendo la parte más vulnerable en estos vínculos contractuales derivados de los contratos de adhesión, producto de una relación de consumo de bienes o servicios.

Innegablemente el capitalismo y la industrialización abrieron la puerta al mercado y comercio en masa, cuyo denominador común es la flexibilidad y dinamismo propio de las practicas mercantiles a las que es inherente el consumo; no obstante, esa regla general debe tener excepciones precisas con el fin de garantizar en la medida de lo posible el equilibrio contractual y la libertad de las personas a la hora de elegir un bien o servicio; allí es donde cobra importancia el derecho al consumo que casi con ánimo de "salvador" aparece en respuesta a las necesidades que evidenciaban la práctica del consumo desmedido y predispuesto por la parte dominante a la que pertenecen el gran grupo de productores y proveedores.

En lo referente a la evolución de las regulaciones vale la pena mencionar la importancia del reconocimiento hecho al contrato de adhesión y más que al contrato de adhesión, el reconocimiento a la posibilidad de que dentro de su contenido pudiera involucrarse una cláusula de tipo "abusiva", pues ello permitió al legislador actuar, generando un avance normativo con el cual, indefectiblemente, lo dispuesto evidencia una materialización de un marco de protección para el consumidor, en quien radica el objeto de la actual Ley 1480 de 2011; se concreta el listado de cláusulas abusivas y, junto con ello, se pone una alarma a las entidades de control, a quienes queda la verificación del cumpli- 
miento de lo dispuesto, ya per se o por la posibilidad que tienen consumidores y usuarios de manifestar quejas y reclamos por el producto percibido.

Sin lugar a dudas, aun es extenso el sendero que tanto normativa como materialmente queda por recorrer en términos de derecho del consumo; no obstante, ese primer paso dado por el reconocimiento jurídico a los derechos del consumidor en Colombia ya está consolidado y se materializó con el Estatuto del Consumidor que nos ubica a todos en un escenario bajo el que gozamos de unas verdaderas garantías y de un efectivo régimen de protección frente a los posibles abusos en incurra el sector productor (tanto de bienes como de servicios). Igualmente, sirve resaltar como los regímenes especiales que de manera paralela o anterior al Estatuto, fueron desarrollados, se consolidan también como una herramienta complementaria de lo previsto de manera general, con lo que no solo tenemos garantías, sino que a la par con las disposiciones de estos regímenes, tenemos también las herramientas normativas para hacerlas efectivas.

El panorama es bastante prometedor, lo que queda ahora es dotar a ese sistema normativo de mayores instrumentos que permitan evidenciar con más notoriedad, en la práctica, el régimen proteccionista y garantista que este ha consolidado en materia de derecho del consumo, el cual sigue alimentándose de lo que día a día los pronunciamientos de las distintas autoridades en la materia, especialmente la Superintendencia de Industria y Comercio, disponen en desarrollo de su labor y en complementariedad de lo ya dispuesto.

\section{REFERENCIAS}

Alvarez, J. (2012). La libertad contractual del consumidor en Colombia: ¿Mito o realidad? Extraído Junio 2012, desde http://www.curn. edu.co/revistas/ergaomnes/vol2009/9.pdf. Arrubla, J. (1986). Contratos civiles y mer- cantiles. Bogotá: Editor: Juan Carlos Berrocal Duran.

Banol. A. \& Pérez, Y. (1991). Intervención del Estado y normas de protección al consumidor. Medellín: Asociación de consumidores de Medellín.

Cámara de Comercio, Foro del Jurista (2012). Estatuto del Consumidor. Una mirada a la Ley 1480 de 2011. Medellín: Cámara de Comercio. Ed. núm. 29.

Circular Externa 039 del 6 de septiembre de 2011. Superintendencia Financiera, Colombia.

Concepto 05063562 del 13 de marzo de 2006. Superintendencia de Industria y Comercio, Colombia.

Concepto 2007001302-001 del 23 de febrero de 2007. Superintendencia Financiera, Colombia.

Concepto 22009074985-004 del 26 de noviembre de 2009. Superintendencia Financiera, Colombia.

Concepto 674 del 23 de noviembre de 2011. Superintendencia de Servicios Públicos Domiciliarios, Colombia.

Concepto 95561 de febrero 29 de 2012. Superintendencia Financiera, Colombia.

Constitución Política de Colombia [Const]. Julio 7 de 1991 (Colombia).

Corte Constitucional de Colombia. Sentencia C - 1141 de 2000 (MP. Eduardo Cifuentes Muñoz; Agosto 30 de 2000).

Corte Constitucional de Colombia. Sentencia C- 973 de 2002 (MP. Álvaro Tafur Galvis; Noviembre de 2002).

Corte Constitucional de Colombia. Sentencia C-1141 del 2000 (MP. Eduardo Cifuentes Muñoz; Agosto del 2000). 
Corte Constitucional de Colombia. Sentencia C-1162 de 2000 (MP. José Gregorio Hernández Galindo; Septiembre 6 de 2000)..

Corte Constitucional de Colombia. Sentencia C-909 de 2012(MP. Nilson Pinilla Pinilla; Noviembre 7 de 2000).

Corte Constitucional de Colombia. Sentencia SU-1010 de 2008 (MP. Rodrigo Escobar Gil; Octubre 16 de 2000).

Corte Constitucional de Colombia. Sentencia T-136 de 2013 (MP. Jorge Iván Palacio Palacio; Marzo 13 de 2013).

Chavarro, J. (2012). Comentarios al estatuto del consumidor. Bogotá: Colombia Nueva Legislación.

Decreto 3466 de 1982. Por el cual se dictan normas relativas a la idoneidad, la calidad, las garantías, las marcas, las leyendas, las propagandas y la fijación pública de precios de bienes y servicios, la responsabilidad de sus productores, expendedores y proveedores, y se dictan otras disposiciones. Diciembre 3 de 1982. Diario Oficial N ${ }^{\circ} 33559$.

Decreto 663 de 1993. Por medio del cual se actualiza el estatuto orgánico del sistema financiero y se modifica su titulación y numeración. Abril 5 de 1993. Diario Oficial № 40820.

Diez, L. (1997). Las condiciones generales de la contratación. Madrid: Civitas.

Directiva 93/13 de 5 de abril de 1993, sobre las cláusulas abusivas en los contratos celebrados con consumidores. Comunidad Económica Europea, Unión Europea.

Echeverry, V. (2011, Julio-Diciembre). El control a las cláusulas abusivas en los contratos de adhesión con los consumidores. Opinión Jurídica, 10, 20, 125-144.
Escobar, G. (1996). Negocios civiles y comerciales. Bogotá: Universidad Externado de Colombia.

Farina, J. (2005). Contratos comerciales modernos. Buenos Aires, Argentina: Astrea.

Gual, J. \& Villalba, J. (2013). Derecho del consumo, problemáticas actuales. Bogotá: Ibánez.

Ley 1328 de 2009. Por la cual se dictan normas en materia financiera, de seguros y de mercado de valores y otras disposiciones. Julio 15 de 2009. Diario Oficial $N^{\circ} 47411$.

Ley 1341 de 2009. Por la cual se definen principios y conceptos sobre la sociedad de la información y la organización de las tecnologías de la información y las telecomunicaciones (TIC), se crea la agencia nacional del espectro electromagnético y se dictan otras disposiciones. Julio 30 de 2009. Diario Oficial N 47426.

Ley 142 de 1992. Por la cual se establece el régimen de los servicios públicos domiciliarios y se dictan otras disposiciones. Julio 11 de 1994. Diario Oficial № 41433.

Ley 1480 de 2011. Por la cual se expide el estatuto del consumidor y se dictan otras disposiciones. Abril 12 de 2012. Diario Oficial $N^{\circ}$ 48220.

López, R. (2004). Las cláusulas abusivas en el derecho brasilero, en contratación contemporánea. Lima: Culzoni.

Ossorio, M. (1981). Diccionario de Ciencias jurídicas, políticas y sociales. Buenos Aires: Heliasta.

Pérez, L. (2004). Derecho del consumidor. Buenos Aires: Astrea.

Rengifo, E. (2003). Del abuso del derecho de la posición dominante. Bogotá: Universidad Externado de Colombia. 
Resolución 1732 del 7 de septiembre de 2007. Comisión de Regulación de Telecomunicaciones, Colombia.

Resolución 3066 del 18 de mayo de 2011. Comisión de Regulación de Telecomunicaciones, Colombia.

Resolución 31471 del 23 de mayo de 2012. Superintendencia de Industria y Comercio, Colombia.

Santos, J. (1978). Derecho económico y derecho civil. Madrid: Dilex.

Stiglitz, R. (1997). Derechos y defensa del consumidor. Buenos Aires: Juris.

Suescún, F. (2009). Control judicial de las cláusulas abusivas en Colombia: una nueva causal de nulidad. Revista de Derecho Privado, 41 Universidad de los Andes. Extraído Septiembre, 2009, desde http://derechoprivado.unian- des.edu.co/components/com_revista/archivos/ derechoprivado/pri111.pdf

Suescún, J. (2003). Estudios de derecho privado: Civil y mercantil. Bogotá: Legis.

Superintendencia de Industria y Comercio. (1998). Política y derechos del consumo. Bogotá.

Villalba, J. (2009, Julio-Diciembre). Aspectos introductorios al derecho del consumo". Prolegómenos: Derechos y valores, 12, 24, 77-95.

Villalba, J. (2011, Diciembre). Los contratos de consumo en el derecho colombiano y el derecho comparado. Revista Facultad de Ciencias Económicas: Investigación y Reflexión, 19, 2, 171-195.

Villalba, J. (2012). Introducción al derecho del consumo. Bogotá: Universidad Militar Nueva Granada. 